\title{
Caracterização físico-química do colostro de búfalas na primeira ordenha pós-parto por meio de absorção infravermelha*
}

\author{
Physico-chemical characterization of buffalo colostrum at the first \\ postpartum milking by infrared absorption
}

\author{
Emerson Gabriel dos Santos Oliveira, ${ }^{*}$ Adriano Henrique do Nascimento Rangel, ${ }^{* *}$ Danielle Calvalcanti Sales, ${ }^{* \star *}$ \\ Jodailza da Silva Bezerra, ${ }^{* * *}$ Emanuelle Patrícia Enrique da Silva, ${ }^{*}$ Yhelda Maria de Oliveira Silva, ${ }^{*}$ \\ Luiz Henrique Fernandes Borba, ${ }^{* *}$ Dorgival Morais de Lima Júnior ${ }^{* * * *}$
}

\begin{abstract}
Resumo
Objetivou-se caracterizar o colostro da primeira ordenha de búfalas da raça Murrah utilizando a metodologia não oficial de absorção infravermelha. Para isso, foram colhidas amostras individuais de 42 fêmeas multíparas, por meio de ordenha manual. As amostras foram coletadas em até $12 \mathrm{~h}$ após o parto e encaminhadas para determinação de gordura, proteína, lactose, sólidos totais e sólidos não gordurosos por meio de absorção infravermelha. Realizamos também a contagem de células somáticas (CCS) e leitura de condutividade elétrica (CE) do colostro. Os dados foram submetidos à análise estatística descritiva através do procedimento proc means. Os valores de condutividade elétrica foram divididos em quatro classes e as médias das características físico-químicas das diferentes classes foram comparadas pelo teste T com $5 \%$ de significância. Também foi realizada análise de correlação entre as características químicas, CCS e CE do colostro. Foram obtidas médias de 4,34 $\pm 3,24 \%$ para gordura, 11,88 $\pm 3,93 \%$ para proteína, $2,54 \pm 0,9 \%$ para lactose, $10,01 \pm 3,33 \%$ para caseína, $26,56 \pm 4,18 \%$ para sólidos totais, $16,20 \pm 3,70 \%$ para sólidos não gordurosos, 316,86 $\pm 341,56$ mil células somáticas, e 4,44 $\pm 0,81 \mathrm{mS} \mathrm{cm}^{-1}$ para condutividade elétrica do colostro. O colostro de búfalas ordenhadas em até $12 \mathrm{~h}$ pós-parto apresenta elevado teor de proteína. Além disso, observamos que quanto maior a leitura da condutividade elétrica, menores são os percentuais de proteína, caseína e sólidos não gordurosos no colostro.
\end{abstract}

Palavras-chave: composição do colostro, condutividade elétrica, qualidade do colostro.

\begin{abstract}
The objective of this study was to characterize the colostrum of the first milking of buffaloes of the Murrah breed using the infrared absorption. For this, individual samples of 42 multiparous females were collected by manual milking. Samples were collected up to $12 \mathrm{~h}$ after delivery and sent for determination of fat, protein, lactose, total solids and non-greasy solids by the infrared absorption method. We also performed somatic cell counts (SCC) and electric conductivity (EC) reading of colostrum. The data were submitted to descriptive statistical analysis through the procedure proc means. The values of electrical conductivity were divided into four classes and the means of physical-chemical characteristics of the different classes were compared by the T test with $5 \%$ significance. A correlation analysis was also performed between the chemical characteristics, SCC and EC of colostrum. Averages of $4.34 \pm$ $3.24 \%$ for fat, $11.88 \pm 3.93 \%$ for protein, $10.01 \pm 3.33 \%$ for casein, $2.54 \pm 0.9 \%$ for lactose, $26,56 \pm 4.18 \%$ for total solids, $16.20 \pm$ $3.70 \%$ for non-greasy solids, $316.86 \pm 341.56$ mil somatic cells and $4.44 \pm 0.81 \mathrm{mS} \mathrm{cm}-1$ for electrical conductivity of colostrum. The colostrum of milked buffaloes up to 12 hours postpartum presents high protein content. In addition, we observed that the higher the electrical conductivity reading, the lower the percentages of protein, casein and non-greasy solids in colostrum.
\end{abstract}

Keywords: colostrum composition, colostrum quality, electrical conductivity.

\section{Introdução}

Embora ocorra em todos os mamíferos, a ingestão de colostro possui importância destacada para os herbívoros ruminantes. Devido ao tipo de placenta, nesses animais, os anticorpos maternos são transferidos apenas por meio da ingestão do primeiro leite pós-parto, rico em imunoglobulinas. Desta forma, para sua sobrevivência, o ruminante recém-nascido necessita consumir o colostro não só para receber os nutrientes, mas principalmente as imunoglobulinas ali presentes (imunidade passiva) para estar apto às suas primeiras respostas imunológicas (Singh e Pathak, 2013).

*Recebido em 16 de fevereiro de 2018 e aceito em 29 de julho de 2018.

*Discente do Programa de Pós-graduação em Produção Animal (UFRN/UFERSA). Macaíba, Rio Grande do Norte, Brasil.

**Docente permanente do Programa de Pós-graduação em Produção Animal (UFRN/UFERSA). Macaíba, Rio Grande do Norte, Brasil.

***Discente do Programa de Pós-graduação em Zootecnia da Unesp. Jaboticabal, São Paulo, Brasil.

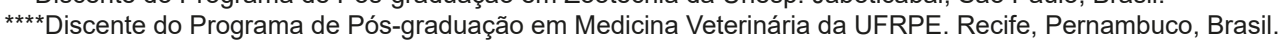

${ }^{* * * * *}$ Docente do curso de Zootecnia da UFAL/Campus Arapiraca. Arapiraca, Alagoas, Brasil. e-mail: juniorzootec@yahoo.com.br. 
A composição química do colostro varia entre as diferentes espécies mamíferas, no entanto, geralmente é rico em energia, proteína, vitaminas e minerais (Dang et al., 2009). Na espécie bubalina os teores de sólidos totais vaiam de 25,31-26,67\%, 9,59-11,31\% de gordura, 8,73-13,46\% de proteína e 3,73\% de lactose (Abd El-Fattah et al., 2012; Corian et al., 2013). As imunoglobulinas constituem de 70 a $80 \%$ da proteína total do colostro (McGrath et al., 2016). Enquanto que a gordura é predominantemente constituída de ácidos butírico $(\mathrm{C} 4: 0)$, misrístico (C14:0), palmítico (C16:0), esteárico (C18:0) e oleico (C18:1) (Corian et al., 2013). Esse pool de constituintes do colostro suporta a nutrição básica, o crescimento e desenvolvimento da cria, tem ação imunorregulatória e antiinflamatória, além de modular funções digestivas e a microflora intestinal (Ashok e Aparna, 2017; Golinelli et al., 2014; Nissen et al., 2017).

Os búfalos são ruminantes comuns no continente asiático e explorados em sua maioria para produção de leite (FAO, 2017). Porém, a criação de bezerros dessa espécie esbarra no conhecimento escasso sobre os aspectos nutricionais do leite e do colostro bubalino (Dang et al., 2009). Principalmente para subsidiar a formulação de sucedâneos e dietas para as crias.

Uma forma rápida e robusta de caracterizar a composição do leite é através da absorção infravermelha (Wojciechowski et al., 2016), tendo aplicação inclusive na determinação de derivados lácteos, como soro de leite (Pinto et al. 2011). Todavia, não existem estudos que caracterizem o colostro de búfalas utilizando a absorção infravermelha. Dessa forma, objetivamos determinar a composição química do colostro da primeira ordenha de búfalas da raça Murrah por meio de absorção infravermelha.

\section{Material e métodos}

O projeto deste estudo foi submetido ao Comitê de Ética em Uso Animal - CEUA sob o protocolo 007/2015, sendo aprovado para implementação do ponto de vista legal, de acordo com a Lei $n^{\circ}$ 11.794, 2008.

O estudo foi conduzido em uma fazenda particular situada na cidade de Taipu, região Agreste do estado do Rio Grande do Norte, Brasil ( $5^{\circ} 37^{\prime} 18^{\prime \prime}$ latitude Sul e $35^{\circ} 35^{\prime} 48^{\prime \prime}$ longitude Oeste, a $41 \mathrm{~m}$ acima do nível do mar). Pela classificação Köppen o clima é caracterizado por $A S$, com época chuvosa de fevereiro a julho e seca de agosto a janeiro. A precipitação média anual em 2015 foi de $603 \mathrm{~mm}$, a temperatura média de $25,3{ }^{\circ} \mathrm{C}$ e a umidade relativa média de $70 \%$ (EMPARN, 2015).

Foram utilizadas 42 búfalas multíparas da raça Murrah, mantidas em piquetes de Urochloa brizantha, Urochloa humidicola e Megathyrsus maximum cv. Massai e recebiam 2,0 kg de concentrado ao dia, a partir dos 60 dias antes do parto.

Foram obtidas amostras individuais de colostro das 42 búfalas leiteiras saudáveis na sua primeira ordenha em até 12 horas após o parto. Essas amostras foram colhidas diretamente dos tetos dos animais através de ordenha manual, em frascos plásticos com capacidade de $40 \mathrm{~mL}$, acondicionadas em caixa isotérmicas com gelo a uma temperatura entre 3 a $7^{\circ} \mathrm{C}$ e encaminhadas para análises no laboratório de Qualidade do Leite da Universidade Federal do Rio Grande do Norte (LABOLEITE/UFRN).

As amostras de colostro foram submetidas à análise para a determinação da gordura, proteína total, lactose, caseína, sólidos totais e sólidos não gordurosos em instrumento de absorção infravermelha (Bentley $2000^{\circledR}$, Bentley Instruments Inc, Chaska, Minnesota, USA). A calibração do equipamento foi realizada por dados não-corrigidos, obtidas de amostras-padrão de colostro de búfalas enviadas bimestralmente, as quais foram preparadas através de métodos químicos.

A contagem de células somáticas foi realizada em analisador automático baseado em método de viscosidade com faixa de medição de 90 a 1.500 x $10^{3}$ céls $\mathrm{mL}^{-1}$ (Ekomilk ${ }^{\circledR}$, Eon Trading Inc, Bulgaria).

Para a mensuração da condutividade elétrica (CE), as amostras foram submetidas ao teste que avalia a troca entre cátions e ânions presentes no colostro por meio de um medidor portátil (Ak83, $\mathrm{Akso}^{\circledR}$, Rio Grande do Sul, Brasil), com faixa de medição

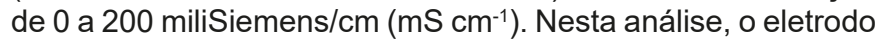
foi submerso nas amostras de colostro, permitindo que ocorresse a passagem de corrente elétrica, registrada em visor digital.

Os dados foram submetidos à análise descritiva, através da qual foi obtida a média, desvio-padrão e coeficiente de variação de cada variável do estudo.

Os valores de Condutividade Elétrica (CE) foram divididos em quatro classes. A Classe 1 apresenta valores de CE menores que 3,73; a classe 2 apresenta valores de CE entre 3,73 e 4,52; a classe 3 apresenta valores de CE entre 4,53 e 5,72; e a classe 4 apresenta valores de CE maiores que $5,72 \mathrm{mS} \mathrm{cm}^{-1}$. Para comparação de médias das características do colostro dentro das classes de CE foi empregado o teste $T$ ao nível de significância de $5 \%$, em virtude do número de classes e do alto coeficiente de variação das características.

Adicionalmente foi obtido o Coeficiente de Correlação de Pearson para se avaliar a associação entre CE e CCS com os constituintes químicos do colostro.

As análises estatísticas foram realizadas no Statistical Analyses System, 2002 (SAS Institute Inc., Cary - NC, USA).

\section{Resultados e discussão}

Os valores para as médias das percentagens de gordura, proteína total, lactose, caseína, sólidos totais, sólidos não gordurosos, contagem de células somáticas e condutividade elétrica do colostro bubalino com até 12 horas pós-parto encontram-se na Tabela 1.

Os percentuais de gordura, proteína, lactose, sólidos totais e não gordurosos apresentam-se próximos aos relatados por Arain et al. (2008) e Kamel et al. (2015) para o colostro de búfalas.

Arain et al. (2008) observaram valores de 5,79\% de gordura, $12,01 \%$ de proteína total, 3,12\% de lactose, $21,99 \%$ de sólidos totais e $16,20 \%$ de sólidos não gordurosos no colostro nas primeiras 12 horas pós-parto. Entretanto, estes autores encontraram $4,59 \%$ de caseína, valor muito abaixo do encontrado 
Tabela 1: Número de observações $(\mathrm{N})$, valores mínimo (Min) e máximo (Max), valores médios, desvio padrão (SD) e coeficiente de variação (CV) das características do colostro de búfalas na primeira ordenha pós-parto

\begin{tabular}{lccccc}
\hline Característica, Unidade & N & Média \pm SD & Min & Max & CV \\
\hline Gordura, \% & 42 & $4,34 \pm 3,24$ & 0,26 & 13,41 & 74,69 \\
Proteína, \% & 42 & $11,88 \pm 3,93$ & 4,49 & 19,73 & 33,11 \\
Caseína, \% & 42 & $10,01 \pm 3,33$ & 3,80 & 16,66 & 33,30 \\
Lactose, \% & 42 & $2,54 \pm 0,9$ & 0,49 & 4,50 & 35,61 \\
Sólidos Totais, \% & 42 & $20,56 \pm 4,18$ & 5,80 & 32,02 & 20,34 \\
Sólidos Não Gordurosos, \% & 42 & $16,20 \pm 3,70$ & 5,53 & 23,84 & 22,85 \\
Contagem de Células Somáticas, $\times 10^{3}{\text { céls } \mathrm{mL}^{-1}}^{-1}$ & 35 & $316,86 \pm 341,56$ & 89,00 & 1489,00 & 107,79 \\
Condutividade Elétrica, mS cm ${ }^{-1}$ & 41 & $4,44 \pm 0,81$ & 2,93 & 6,12 & 18,45 \\
\hline
\end{tabular}

no presente estudo, essa diferença pode estar relacionada ao método de análise, já que Arain et al. (2008) utilizaram análise química oficial em que a caseína é precipitada para $\mathrm{pH}$ 4,6 e o precipitado é analisado pelo método de Kjeldahl. Os valores elevados de proteína no colostro estão relacionados com a alta quantidade de imunoglobulinas transferidas da corrente sanguínea materna no período colostral. Por este motivo, o percentual de proteína do colostro encontrado neste estudo é mais acentuado de que o percentual médio de proteína do leite bubalino maduro.

No colostro há três tipos de imunoglobulinas particularmente importantes: IgG, que são os menores anticorpos, porém de maior proporção em relação aos demais e têm um papel fundamental na luta contra infecções bacterianas e virais; $\lg \mathrm{A}$, que protege as superfícies do corpo contra substâncias externas; $\mathrm{E}$ a IgM, maior anticorpo e o primeiro produzido em resposta a uma infecção (Dang et al., 2009).

Os níveis mais altos dessas imunoglobulinas nos ruminantes são encontrados durante a colostrogenese, que coincide com o período de máxima eficiência na absorção desses anticorpos pelo epitélio intestinal do bezerro. Depois do período de colostrogenese, a concentração das imunoglobulinas reduz gradativamente (leite de transição), o que acarreta diminuição do percentual da proteína total e consequentemente de sólidos totais e sólidos não gordurosos, até que se atinja a composição do leite (Abd El-Fattah et al., 2012; Arian et al., 2008; Coroian et al., 2013; Dang et al., 2009).

Apesar de ter sido encontrado um baixo valor para lactose, Arian et al. (2008) e Kamel et al. (2015) relatam que o percentual da lactose do colostro bubalino cresce ao longo da transição do colostro para leite, acompanhando o aumento do volume secretado. A expressão de genes que originam enzimas envolvidas na síntese de lactose na glândula mamária é baixa imediatamente ao preiparto, mas tende a aumentar no decorrer da lactação (Lin et al., 2016).

No leite de fêmeas recém-paridas, a Contagem de Células Somáticas (CCS) é interessante para atestar as condições em que as mesmas entraram na nova lactação. Foi encontrada uma média de CCS em 316,85 $\pm 341,56 \times 10^{3}$ céls $\mathrm{mL}^{-1}$ de colostro, valor que supera as $200 \times 10^{3}$ céls $\mathrm{mL}^{-1}$ adotadas como indicativo de inflamação da glândula mamária de vacas e búfalas (Moura et al., 2017a; Tripaldi et al., 2010). Entretanto, no colostro das primeiras $24 \mathrm{~h}$ após o parto, Dang et al. (2009) encontraram média de $500 \times 10^{3}$ céls $\mathrm{mL}^{-1}$, valor significativamente maior em relação ao encontrado no nosso estudo.

Altas contagens de células somáticas no colostro podem estar relacionadas com a fase fisiológica dos animais e não necessariamente com um quadro inflamatório, porque as alterações glandulares durante a colostrogenese podem culminar naturalmente com o aumento fisiológico da CCS no primeiro colostro produzido (Reis et al., 2016). Essas alterações resultam do desprendimento natural de células secretoras a partir do alto curso secretório iniciado nesta fase; a baixa proporção e atividade de neutrófilos; e alta proporção e atividade fagocitária de macrófagos (Dang et al., 2009; Reis et al., 2016; Tripaldi et al., 2010).

Segundo Kamel et al. (2015), a condutividade elétrica (CE) do leite se refere a uma medida da resistência do leite a uma corrente elétrica, sendo expressa pela concentração de ânions e cátions $\left(\mathrm{Na}^{+}, \mathrm{K}^{+}\right.$e $\left.\mathrm{CL}^{-}\right)$. Em casos de inflamação da glândula mamária, ocorre desequilíbrio de minerais, o que permite que os valores mais altos de CE do leite sejam tomados como indicativo da doença.

No colostro de búfalas com até 12 horas após o parto, obtivemos valor médio de CE igual a $4,44 \mathrm{mS} \mathrm{cm}^{-1}$ (Tabela 2). Para o leite de vacas livres de mastite são aceitos valores entre 4 e 5,5 $\mathrm{mS} \mathrm{cm}^{-1}$ a $25^{\circ} \mathrm{C}$ (Kamel et al., 2015) e para búfalas, valores entre 1,5 e 3,0 mS cm$~_{-1}$ (Moura et al., 2017a). Raimondo et al. (2009) observaram o maior valor médio de CE $\left(6 \mathrm{mS} \mathrm{cm}^{-1}\right)$ na fase colostral de vacas da raça Jersey no período entre 12 e 24 horas pós-parto.

Quando distribuímos as amostras de colostro em diferentes classes de condutividade elétrica, observamos diferenças em relação às suas características físico-químicas (Figura 1).

A Classe 1 e a Classe 2 tiveram o valor de CE mais próximo de $3,82 \mathrm{mS} \mathrm{cm}^{-1}$, média encontrada no leite de búfalas em início de lactação (Bastos e Birgel, 2011), demonstrando que as classes 3 e 4 não estão enquadradas no que se espera para o colostro bubalino.

A composição química do colostro nas classes com CE abaixo de $5,3 \mathrm{mS} \mathrm{cm}^{-1}$ (Classe 1, Classe 2 e Classe 3) é estatisticamente semelhante. A classe $1(\mathrm{CE}<3,73)$ apresenta maiores valores para proteína e sólidos totais e a classe 4 (CE $\geq 5,33$ ), menores valores de lactose (Figura 1). Fato semelhante pode ser observado no leite de vacas zebuínas, em que as classes com maior percentual de gordura, proteína e sólidos totais, e menor percentual de lactose eram as de menor CE (Moura et al., 2017b).

As amostras de colostro de búfalas com CE menor que 5,3 $\mathrm{mS} \mathrm{cm} \mathrm{cm}^{-1}$ apresentaram os maiores percentuais de sólidos não gordurosos (SNG). O colostro apresenta maior concentração de minerais e menor proporção de gordura em relação ao leite (Kamel et al., 2015), permitindo que a condutibilidade dos cátions e ânions no colostro se dê com menor resistência. 


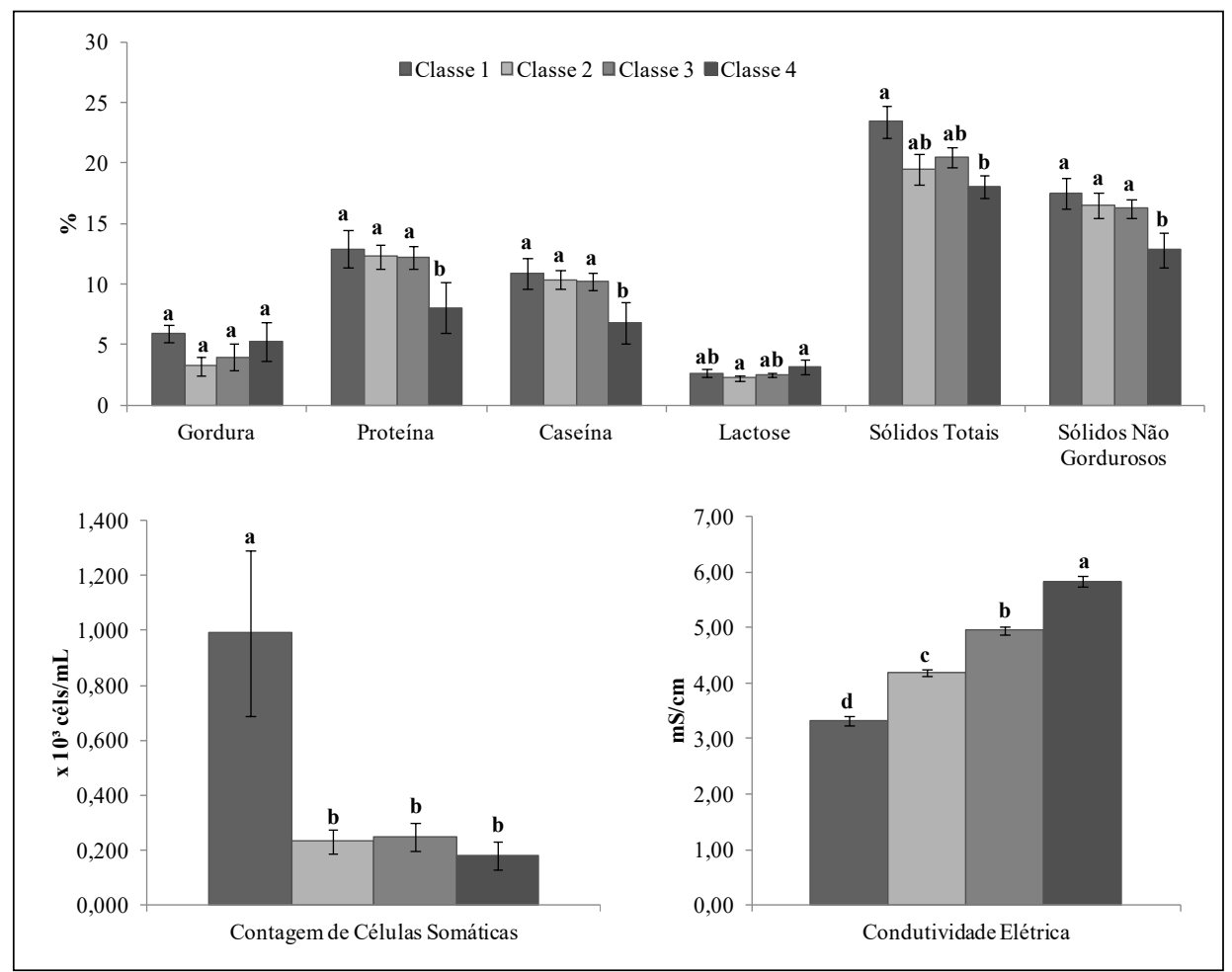

Figura 1: Médias para as características do colostro de búfalas na primeira ordenha pós-parto, de acordo com quadro classes de condutividade elétrica $(E C)$ - classe $1(E C<3,73 ; n=9)$; classe $2(3,73<E C<4,52$; $n=14)$; classe $3(4,53<E C<5,32 ; n=13)$; e classe $4(E C \geq 5,33 ; n=5)$

O maior percentual de gordura, proteína, sólidos totais, caseína e sólidos não gordurosos foi encontrado na classe de menor condutividade elétrica, relação semelhante foi observada por no leite de zebuínos (Moura et al., 2017b). Dessa forma, a condutividade elétrica pode ser uma ferramenta de estimativa do valor nutritivo do colostro de búfalas.

O coeficiente de correlação de Pearson entre a CE e a CCS do colostro de búfalas foi igual a $-0,461(P=0,005)$.

\section{Referências}

ABD EL-FATTAH, A.M.; ABD RABO, F.H.; EL-DIEB, S.M.; ELKASHEF, H.A. Changes in composition of colostrum of Egyptian buffaloes and Holstein cows. BMC Veterinary Research, v.8, n.1, p.19, 2012.

ABD EL-SALAM, M.H.; EL-SHIBINY, S. A comprehensive review on the composition and properties of buffalo milk. Dairy Science \& Technology, v.91, n.663, 2011.

ANDRADE, K. D.; RANGEL, A. H. N.; ARAÚJO, V. M.; LIMA JÚNIOR, D. M.; OLIVEIRA, N. A. Efeito da estação do ano na qualidade do leite de búfalas. Revista Verde de Agroecologia e Desenvolvimento Sustentável, v.6, n2, p.33-37, 2011.

ARAIN, H.H.; KHASKHELI, M.; ARAIN, M.A.; SOOMRO, A.H.; NIZAMANI, A.H. Heat stability and quality characteristics of postpartum buffalo milk. Pakistan Journal of Nutrition., v.7, n. 2, p.303-307, 2008.

ASHOK, N.R.; APARNA, H.S. Empirical and bioinformatic characterization of buffalo (Bubalus bubalis) colostrum whey peptides \& their angiotensin l-converting enzyme inhibition. Food Chemistry, v.228, n.4, p.582-594, 2017.

\section{Conclusão}

Dentre os constituintes químicos do colostro, a CCS se correlacionou somente com os sólidos totais $(r=$ 0.409; $\mathrm{P}<0,01$ ), o que corrobora os resultados encontrados por Barreto et al. (2010), que não observaram correlação entre a CCS, gordura, sólidos não gordurosos e proteína total do leite bubalino. Contrariamente, Dang et al. (2009) encontraram uma correlação positiva entre a CCS e a proteína total e correlação negativa entre a CCS e a lactose no colostro de búfalas.

A CE apresentou correlação significativa $(P<0,01)$ com proteína $(-0,321)$, caseína $(-0,322)$, sólidos totais $(-0,326)$ e sólidos não gordurosos $(-0,315)$. Apesar de se conhecer a relação inversa entre gordura e condutibilidade, não foi encontrada correlação significativa entre essas duas variáveis. Bastos e Birgel (2011) observaram correlação positiva entre condutividade elétrica e lactose, fato não evidenciado nesse estudo com o colostro da primeira ordenha após o parto.

O colostro de búfalas Murrah nas primeiras 12 horas pós-parto, caracterizado por meio da absorção infravermelha, apresentou valores entre 4,49\% e 19,73\% para proteína total, 3,8\% e 16,66\% para caseína, $0,26 \%$ e $13,41 \%$ para gordura, $5,8 \%$ e $32,02 \%$ para sólidos totais, 5,53\% e 23,84\% para sólidos não gordurosos, 2,93 e $6,12 \mathrm{mS} \mathrm{cm}^{-1}$ para condutividade elétrica e 89 e 1.489 x $10^{3}$ céls $\mathrm{mL}^{-1}$ para contagem de células somáticas.

BARRETO, M. L. J.; RANGEL, A.H.N.; ARAUJO, V.M.; BEZERRA, K.C.; MEDEIROS, H.R.; OLIVEIRA, J.P.F.; ANDRADE, K.D. Análise de correlação entre a contagem de células somáticas (CCS), a produção, o teor de gordura, proteína e extrato seco total do leite bubalino. Agropecuária Científica no Semi-árido, v.6, n.2, p.47-53, 2010.

BASTOS, P. A. S.; BIRGEL, E. H. Leite de búfalas Murrah criadas em São Paulo (Brasil): influência da idade, fase de lactação, momento da ordenha e isolamento bacteriano na composição físico-química e celular. Revista de Educação Continuada em Medicina Veterinária e Zootecnia, v.9, n.3, p.06-13, 2011.

COROIAN, A.; ERLER, S.; MATEA, C.T.; MIREȘAN V.; RĂDUCU, C.; BELE, C.; COROIAN, C.O. Seasonal changes of buffalo colostrum: physicochemical parameters, fatty acids and cholesterol variation. Chemistry Central Journal, v.7, p.40, 2013.

DANG, A. K.; KAPILA, S.; PUROHIT, M.; SINGH, C. Changes in colostrum of Murrah buffaloes after calving. Tropical Animal Health and Production, p.41, n.6, p.1213-1217, 2009.

FAO. Food and Agriculture Organization of the United Nations. Dairy production and products. 2017. Disponível em: <http://www. fao.org >. Acesso em: 22/10/2017. 
GOLINELLI, L. P.; DEL AGUILA, E. M.; PASCHOALIN, V. M. F.; SILVA, J. T.; CONTE-JUNIOR, C. A. Functional aspect of colostrum and whey proteins in human milk. Journal of Human Nutrition \& Food Science, v.2, n.3, p.1035, 2014.

KAMEL, N. N., HAFEZ, Y. M., EL-KHOLY, A. F., MAARECK, Y. A., WARD, G. A. A. Periparturient changes in mammary gland secretions in multiparous buffalo cows (Bubalus bubalis). Advances in Environmental Biology, v.9, p.12-20, 2015.

LIN, Y.; SUN, X.; HOU, X.; QU, B.; GAO, X.; LI, Q. Effects of glucose on lactose synthesis in mammary epithelial cells from dairy cow. BMC Veterinary Research, v. 12, n. 3, p. 81-92, 2016.

McGRATH, B. A., FOX, P. F., McSWEENEY, P. L. H., KELLY, A. L. Composition and properties of bovine colostrum: a review. Dairy Science \& Technology, v. 96, n. 2, p.133-158, 2016.

MOURA, E. O.; RANGEL, A. H. N.; BORBA, L. H. F.; GALVÃO JÚNIOR, J. G. B.; LIMA, G. F. C.; LIMA JÚNIOR, D. M.; DIFANTE, G. S.; URBANO, S. A.; AGUIAR, E. M. Electrical conductivity and somatic cell count in zebu cow's milk. Semina: Ciências Agrárias, v.38, n.5, p.3231-3240, 2017b.

MOURA, E.O.; RANGEL, A. H.N.; MELO, M. C. N.; BORBA, L. H. F.; LIMA JUNIOR, D. M.; NOVAES, L. P.; URBANO, S. A.; ANDRADE NETO, J. C. Evaluation of Microbiological, Cellular and Risk Factors Associated with Subclinical Mastitis in Female Buffaloes. Asian-Australasian Journal of Animal Science, v.30, n.9, p.1340-1349, 2017a.

NISSEN, A.; ANDERSEN, P.H.; BENDIXEN, E.; INGVARTSEN, K.L.; RØNTVED, C.M. Colostrum and milk protein rankings and ratios of importance to neonatal calf health using a proteomics approach. Journal of Dairy Science, v.100, p.2711-2728, 2017.
PINTO, F. A.; FONSECA, L. M., ABREU, L. R.; SOUZA, M. R.; OLIVEIRA, D. L. S.; CLEMENTINO, L. A.; ANDRADE, E. H. P. Método da espectroscopia no infravermelho para análise dos soros de queijos de minas padrão e prato. Arquivo Brasileiro de Medicina Veterinária e Zootecnia, v.63, n.4, p.1039-1042, 2011.

RAIMONDO, R. F. S.; BRACALE-BRANDESPIM, F.; MAZUCCOPRINA, A. P.; BIRGEL JUNIOR, E. H. Avaliação do pH e da eletrocondutividade do leite de bovinos da raça Jersey durante o primeiro mês de lactação. Semina: Ciências Agrárias, v.30, n.3, p.447-456, 2009.

REIS, J.F.; LEITE, R.F.; SILVA, C.P.C.; BACCILI, C.C.; MELVILLE, P.A.; BENITES, N.R.; GOMES, V. Somatic cell counts as an indicator of mammary infection in periparturient cows. Brazilian Journal of Veterinary Research and Animal Science, v. 53, n. 2, p.161-168, 2016.

SINGH, V.P.; PATHAK, V. Physico-chemical changes observed during conversion of murrah buffalo colostrum to milk. Asian Journal of Science and Technology, v.4, p.13-15, 2013.

TRIPALDI, C.; PALOCCI, G.; CATTA, M.; ORLANDINI, S.; AMATISTE, S.; DI BERNARDINI, R.; CATILLO, G. Effects of mastitis on buffalo milk quality. Asian-Australasian Journal of Animal Science, v.23, n.10, p.1319-1324, 2010.

WOJCIECHOWSKI, K. L.; MELILLI, C.; BARBANO, D. M. A proficiency test system to improve performance of milk analysis methods and produce reference values for componente calibration samples for infrared milk analysis. Journal Dairy Science, v. 99, n. 2, p.6808-6827, 2016. 